\title{
OBITUARIES
}

\section{Dr. Howard Clinton Carruthers}

Dr. Howard Clinton Carruthers of Victoria died on February 12, 1981, aged 61. Born in Biggar, Saskatchewan, he taught school for one year before taking a B.A. at the University of Saskatchewan and an M.D. from the University of Manitoba. Following an internship at the St. Boniface Hospital in 1949 there followed general practice in Southern Saskatchewan at Ponteix, Lucky Lake, Davidson and Shaunavon. In the latter community he met his future wife, Jean, who was the matron in the hospital. Deciding to specialise in anaesthesia Howard spent his first two residency years at the Virginia Mason Clinic in Seattle where, under the influence of Dr. Daniel Moore, he developed a life-long interest in regional anaesthesia. Completing his training at the Vancouver General Hospital he passed the Certification examination in 1955 then relocated in Victoria, B.C. Here he was on the staffs of the Victoria General and Royal Jubilee Hospitals, being held in the highest regard as an anaesthetist with special expertise in regional techniques and the management of pain problems.

Howie's popularity was universal among his anaesthetic colleagues, surgeons, nurses and patients. Despite his great clinical abilities he was naturally modest, unfailingly courteous and the possessor of a wonderful prairie sense of humour. He made the art of anaesthesia look deceptively simple due to his vast experience, great technical skill and a wide knowledge of medicine and surgery. An enthusiastic teacher, he was never too busy or too tired to teach an intern or nurse, and many a tyro surgeon in trouble was grateful for his advice. A perpetual student, he attended as many meetings as possible and belonged to the Canadian Anaesthetists' Society, American Society of Anesthesiologists and the International Anesthetic Research Society. He bore his lengthy final illness with uncomplaining courage, as did his family. He will long be remembered fondly by all who knew him and will sadly be missed.

He is survived by his wife Jean, daughters Joan and Susan and a son, Dr. Robert Carruthers, a sister and a brother.

Hugh Macartney

\section{Dr. Richard Proudfoot Douglas}

We record with regret the death of Dr. Richard P. Douglas of Calgary, Alberta, at the age of 71 years. Dr. Douglas graduated M.D. from The University of Toronto in 1935 and was Certificated in Anaesthesia by the Royal College of Physicians and Surgeons of Canada in 1945. After a period of practise at Clinton, Ontario, he joined the Calgary Associate Clinic in 1948. In 1951-52 he represented the Alberta Division on the Council of the Canadian Anaesthetists' Society and in 1974 became a Senior Member of the Society.

Dr. Douglas is survived by his wife Berna and by two sons, two daughters and nine grandchildren. 